\title{
Study of Antibiotic Resistant Pattern of Escherichia coli Isolated from Urinary Tract Infections of Patients of Bangladesh
}

\author{
Reazul Karim*', M. A. Hakim \\ Department of Microbiology, University of Chittagong, Bangladesh
}

Copyright@2018 by authors, all rights reserved. Authors agree that this article remains permanently open access under the terms of the Creative Commons Attribution License4.0 International License

\begin{abstract}
Urinary tract infections (UTIs) are serious health affecting problems worldwide. Urinary tract infection (UTI) can be caused by a lot of bacteria. Among them, $E$. coli is one of the main causes of both nosocomial and community acquired Urinary tract infections in humans. Drug resistance of $E$. coli is becoming alarming with the passage of time worldwide in general and in third world countries in particular. The study was intended to collect and analyze the samples from the patients suffering from Urinary tract infection of two medical of southern region of Bangladesh to reveal the antibiotic resistance pattern of $E$. coli responsible for Urinary tract infection. 50 samples from each hospital were taken. 36 and 41 samples respectively were identified as $E$. coli. Antibiotic sensitivity testing was done on Mueller-Hinton agar by Kirby-Bauer disc diffusion method. All samples exhibited a different percentage of resistance where ciprofloxacin was showed evidence of higher resistance rate, which was $63.88 \%$ and $70.73 \%$ respectively. Higher resistance (63\% \& 75\%) against Ampicillin was also found in patients of both medical. On the other hand, $16 \%$ resistance against ceftriaxone and $23.53 \%$ resistance against cefotaxime suggesting, they were comparatively more effective.
\end{abstract}

Keywords Urinary Tract Infection, E. coli, Antibiotic Resistance Pattern, Antibiotic Sensitivity Test.

\section{Introduction}

Urinary tract infections (UTIs) are defined as the presence of microbial pathogens in the urinary tract with associated symptoms. When it affects the lower urinary tract it is known as cystitis and when it affects the upper urinary tract it is known as pyelonephritis. UTIs are one of the most common bacterial infections seen in primary care, second only to infections of the respiratory tract. [1] They are particularly common among the female population with an incidence of about $1 \%$ of school-aged girls and $4 \%$ of women through child-bearing years. The incidence of infection in females increases directly with sexual activity and child-bearing. In the women, $25-30 \%$ of women between 20-40 years of age will get UTIs. [2] E. coli, E. faecalis, K. pneumoniae, S. marcescens, $P$. aeruginosa, $S$. saprophyticus, $S$. aureus and Proteus mirabilis are most common bacteria causing UTIs in human beings. The $E$. coli accounts for approximately $85 \%$ of community acquired UTIs and 50\% of hospital acquired UTIs. [3] Different factors like age, gender, immune-suppression and urological instruments may affect prevalence of UTIs. [4] Catheter-associated UTIs are one of the most dangerous health risks contributing 34\% of all health care associated infections. [5] UTIs caused by antibiotic-resistant and multiple drug-resistant bacteria have been increased in recent times. Complications in UTIs have increased because of the prevalence of extended-spectrum beta-lactamases (ESBL) producing bacterial pathogens which are also causing many management and epidemiological issues. There were times almost a decade ago, when most of the ESBLs producing organisms were Klebsiellas pp. and mostly were nosocomial. But in recent times the problem has been compounded by the prevalence of ESBL and Multi drug resistance (MDR) E. coli as well. Most of the ESBL E. coli are resistant to a wide range of beta-lactams including cephalosporins, penicillins and piperacillin/ tazobactam, and non beta-lactams including fluoroquinolones, trimethoprim, and gentamycin. [6]. This study was conducted to gain a brief idea about antibiotic resistance pattern of $E$. coli isolated from the patient of two medical of Southern region of Bangladesh, suffering from Urinary tract infection. 


\section{Material and Method}

\section{Sample Collection}

The sample collection procedure was done at the Department of Gynecology and Obstetrics, Noakhali Medical College Hospital and Department of Gynecology and Obstetrics, Chittagong Medical College Hospital. Total 50 samples were collected from each medical college. The age of the patients was 30 to 50. A clean-catch midstream urine sample was collected in a sterile wide mouth container labeled within formation on the patient's age, sex, and brief clinical history. The urine samples from the patients were collected in the early morning before drinking water. Samples from the patients were collected by clean catch of midstream urine the samples were transported immediately to the laboratory of Microbiology Department of the University of Chittagong.

\section{Isolation of Target Pathogen}

After collection, $1 \mathrm{ml}$ from each sample was inoculated into sterile buffer peptone water tubes for the enrichment of microbial growth. The tubes were properly labeled and transported to the laboratory for incubation. All inoculated buffer peptone water tubes were incubated at $37^{\circ} \mathrm{C}$ for 48 hours. After incubation, a loop full culture from each tube was streaked across sterile MacConkey agar plate and Blood agar plate surface. Plates were incubated at $37^{\circ} \mathrm{C}$ for 24-48 hours as per the recommendations of Kass. [8] The plates were incubated at $37^{\circ} \mathrm{C}$ for $24 \mathrm{~h}$ and further incubated for $48 \mathrm{~h}$ in culture (growth) negative cases.

\section{Identification of Isolates}

After isolation, the isolates were identified by standard biochemical tests described in "Bergey's Manual of Determinative Bacteriology”, $8^{\text {th }}$ ed. [9] and $9^{\text {th }}$ ed. [10]. The tests include Gram-staining, Spore staining, Acid-fast staining, starch hydrolysis, Voges Proskauer (V-P) Test, Production of hydrogen sulphide, Gelatin liquefaction test, Nitrate reduction test, Indole test Deep glucose agar test, Catalase reaction Methyl-red test, Fermentation test, Urease test Motility test, Oxidase test Cultural and physiological studies were also done. For further confirmation, rapid Identification kit BBL Crystal $^{\mathrm{TM}}$ Identification Systems Gram-Negative Kit was used. [7].

Total 36 samples from Department of Gynecology and Obstetrics, Noakhali Medical College Hospital and 41 samples from Department of Gynecology and Obstetrics, Chittagong Medical College Hospital was identified as E. coli through standard biochemical tests described in "Bergey's Manual of Determinative Bacteriology", $8^{\text {th }}$ ed. [9] and $9^{\text {th }}$ ed.[10] (Table1) and rapid Identification kit BBL Crystal ${ }^{\mathrm{TM}}$ Identification Systems Gram-Negative Kit (Figure 1). Studies from India have reported E. coli as one of the most common organisms causing UTI. [13-15] In the year 2006, Biswas et. al. studied the prevalence of antimicrobial resistance among urinary isolates in Uttaranchal, India, and in this study, E. coli was isolated from $67.5 \%$ samples and more than $35 \%$ isolates showed resistant to commonly used antibiotics to treat UTI. [16] 
Table 1. Results of Standard Parameter described in Bergey's Manual of Determinative Bacteriology for isolates identified as E. coli

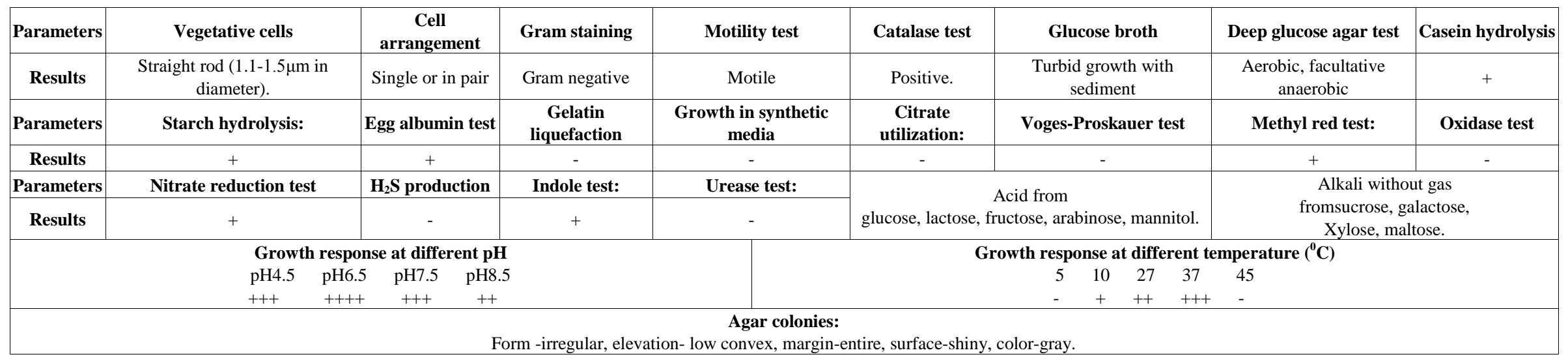

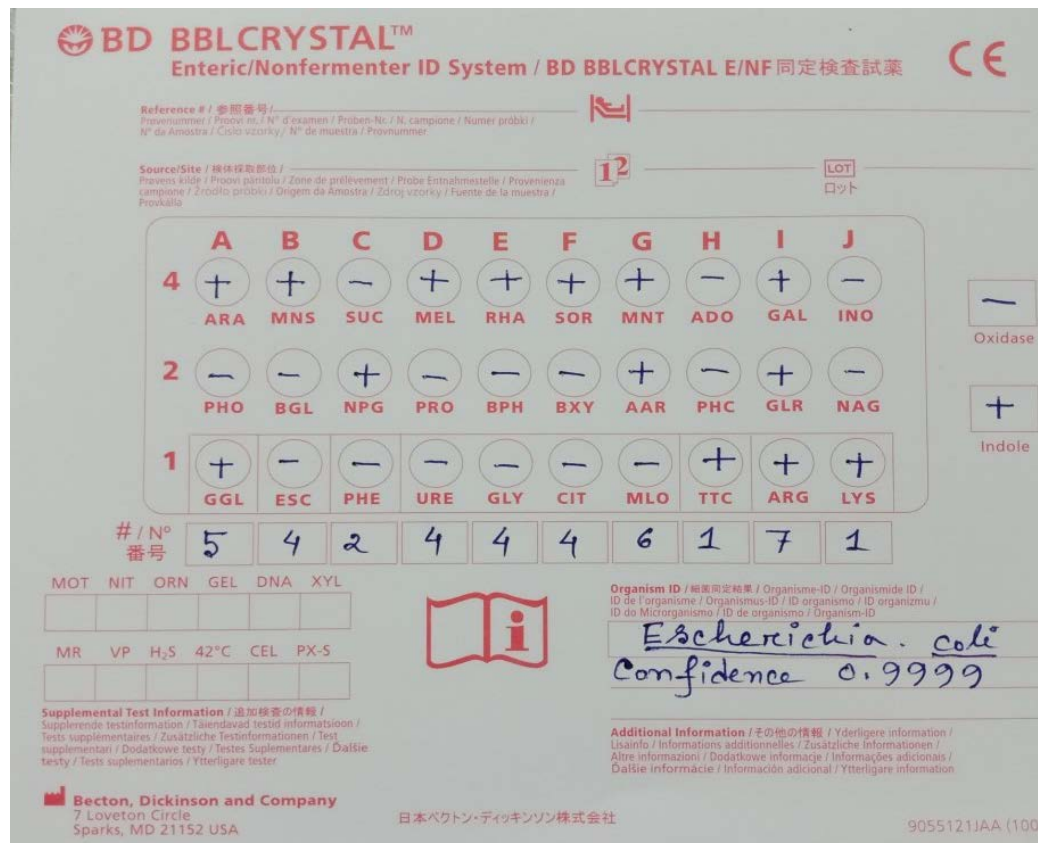

Figure 1. Result of BBL Crystal Gram Negative Identification Kit 


\section{Antimicrobial Susceptibility Test}

Antimicrobial susceptibility tests were done on Mueller-Hinton agar (Oxoid, England) using disc diffusion method [11]. For this test, suspension of the isolates was prepared using sterile distilled water and adjusted to $0.5 \mathrm{McF}$ arland standards. A $100 \mu \mathrm{l}$ suspension of freshly grown bacterial cultures was spread on Mueller Hinton agar plates. The antibiotic discs were placed on the surface of agar and the plates were incubated at $37^{\circ} \mathrm{C}$ for $24-48 \mathrm{hrs}$ Antibiotic disc of gentamicin $(10 \mu \mathrm{g})$, ciprofloxacin $(5 \mu \mathrm{g})$, cefixime $(5 \mu \mathrm{g})$, cefotaxime $(30 \mu \mathrm{g})$, amoxiclav $(30 \mu \mathrm{g})$, ceftriaxone $(30 \mu \mathrm{g})$, ampicillin $(10 \mu \mathrm{g})$, chloramphenicol $(30 \mu \mathrm{g})$ from Oxoid UK was used. The drug susceptibility pattern was interpreted according to Clinical and Laboratory Standards Institute (CLSI, 2014) (formerly known as National Committee for Clinical Laboratory Standards/NCCLS). Reference strains of E. coli ATCC 8739 were used for quality control for antimicrobial susceptibility tests [12]

\section{Ethical Issues}

In the present study, we made an effort to protect the health, privacy, and secrecy of personal information and rights to self-determination of all the participants. All ethical issues were considered and the study was conducted after approval from the institutional review board and with hospital's permission.

\section{Result and Discussion}

Total 36 samples from Department of Gynecology and Obstetrics, Noakhali Medical College Hospital and 41 samples from Department of Gynecology and Obstetrics, Chittagong Medical College Hospital was identified as E. coli. These isolates were then tested for antibiotic susceptibility by disc diffusion method. Below result was found from samples of two medical colleges.

Table 2. Antibiotic susceptibility test result of the samples from Department of Gynecology and Obstetrics, Noakhali Medical College Hospital

\begin{tabular}{|c|c|c|c|}
\hline Antibiotics & Discs & $\begin{array}{c}\text { No of resistant } \\
\text { isolates }\end{array}$ & $\begin{array}{c}\text { \% of resistant } \\
\text { isolates }\end{array}$ \\
\hline gentamicin & $10 \mu \mathrm{g}$ & 12 & 33.33 \\
\hline ciprofloxacin & $5 \mu \mathrm{g}$ & 23 & 63.88 \\
\hline cefixime & $5 \mu \mathrm{g}$ & 11 & 30.55 \\
\hline cefotaxime & $30 \mu \mathrm{g}$ & 19 & 52.77 \\
\hline amoxiclav & $30 \mu \mathrm{g}$ & 9 & 25 \\
\hline ceftriaxone & $30 \mu \mathrm{g}$ & 6 & 16 \\
\hline ampicillin & $10 \mu \mathrm{g}$ & 23 & 63.88 \\
\hline chloramphenicol & $30 \mu \mathrm{g}$ & 8 & 22.22 \\
\hline ampicillin & $10 \mu \mathrm{g}$ & 23 & 63.88 \\
\hline chloramphenicol & $30 \mu \mathrm{g}$ & 8 & 22.22 \\
\hline
\end{tabular}

Table 3. Antibiotic susceptibility test result of the sample from Department of Gynecology and Obstetrics, Chittagong Medical College Hospital

\begin{tabular}{|c|c|c|c|}
\hline Antibiotics & Discs & $\begin{array}{c}\text { No of resistant } \\
\text { isolates }\end{array}$ & $\begin{array}{c}\text { \% of resistant } \\
\text { isolates }\end{array}$ \\
\hline gentamicin & $10 \mu \mathrm{g}$ & 17 & 41.46 \\
\hline ciprofloxacin & $5 \mu \mathrm{g}$ & 29 & 70.73 \\
\hline cefixime & $5 \mu \mathrm{g}$ & 18 & 43.90 \\
\hline cefotaxime & $30 \mu \mathrm{g}$ & 12 & 23.53 \\
\hline amoxiclav & $30 \mu \mathrm{g}$ & 17 & 41.46 \\
\hline ceftriaxone & $30 \mu \mathrm{g}$ & 24 & 58.54 \\
\hline ampicillin & $10 \mu \mathrm{g}$ & 31 & 75.61 \\
\hline chloramphenicol & $30 \mu \mathrm{g}$ & 14 & 34 \\
\hline
\end{tabular}

From the above result, it is clear that all the E. coli isolated from a patient suffering from Urinary tract Infection were resistant to all used antibiotics in different percentage. Higher resistance (63\% \& 75\%) against Ampicillin was found in patient of both medical indicating a cautious use of these antibiotics for the treatment of urinary tract infections. In a similar study, which was conducted by Sabina M. V. et.al., [17], showed highest antimicrobial resistance of E. coli for ampicillin (82,79\%), followed by trimethoprim-sulfamethoxazole $(40,86 \%)$, nalidixicacid (19,35\%), cephazolin (7,52\%), nitrofurantoin (5,37\%), gentamicin (2,15\%) and ciprofloxacin (4,30\%). Patient of Noakhali Medical also showed higher resistance against ciprofloxacin (63\%) and cefotaxime (52\%). Amoxiclav (25\%) and ceftriaxone (16\%) found effective than others. On the other hand, among Chittagong Medical patient, ciprofloxacin (70\%) and ceftriaxone (58\%) was also found resistant and cefotaxime (23\%) was found most effective. The reason for the high resistance to ciprofloxacin observed in this study may be due to increasing an irrational consumption rate, transmission of resistant isolates between people and consumption of food from animals that have received antibiotics. Self-medication, non-compliance with medication and sales of the substandard drug may account for the rise in antibiotic resistance observed in this community. A similar research work was conducted by Sabir. S, et al 2014 [6] where $E$. coli, was reported resistant against beta-lactam antibiotics including cefotaxime (89.7\%), ceftazidime (73.8\%), cephradine (73.8\%), cefuroxime (58.26\%), cefaclor (50\%), Ceftriaxone (43.3\%). In an another similar study [18], antibiogram of uropathogenic E. coli showed that $71 \%$ of the isolates were resistant to cefazolin, $60.42 \%$ to co-trimoxazole, $54.16 \%$ to nalidixic acid, $36.45 \%$ to gentamicin, $9.18 \%$ to ciprofloxacin, $14.58 \%$ to cefepime, $6.25 \%$ to nitrofurantoin and $0.00 \%$ to imipenem and four virulence genes iucD, sfa/focDE, papEF and hly were mainly responsible for developing resistance. From the world wide data it is clear that, antibiotic resistance against conventional drugs is increasing among UTI pathogens. Resistance has emerged even to newer, more potent antimicrobial agents. Among the Gram-negative organisms, 
the highest percentages of resistance were found for E. coli.

\section{Conclusions}

After respiratory tract infection (RTI), UTI is the most common form of infection which is frequently caused by MDR E. coli. In this study, all the E. coli found from two hospitals exhibited a different percentage of resistance where ciprofloxacin and ampicillin was showed evidence of higher resistance. Other drugs displayed variation in resistant pattern. Higher sensitivity was found for cefotaxime and ceftriaxone respectively. More study of imipenem, tazocin, nitrofurantoin,

trimethoprim-sulfamethoxazole should be conducted to reveal detail antibiotic resistance profile. As, the antimicrobial resistance patterns of E. coli causing UTI are highly variable, continuous surveillance of trends in resistance patterns of uropathogens is necessary The treatment of UTI by antimicrobial agents needs to be strongly promoted by in vitro susceptibility testing to evade advance spread of antimicrobial resistance in patients and eventual development of MDR. Study with the combined drug is recommended with follow up of antibiotic sensitivity test.

\section{REFERENCES}

[1] Pushpalatha KS. Urinary tract infection and management. J Night Nursing Times 2008; 4(5):28-32.

[2] Wilma JP. Shafers Medical-Surgical Nursing. 7th edition, B.I. Publications: New Delhi 2002:p.637-40.

[3] Ramanath KV, Shafiya SB. Prescription pattern of antibiotic usage for urinary tract infection treated in a rural tertiary care hospital. Indian J Pharmacy Pract. 2011; 4(2):57-63.

[4] Pondei K, Oladapo O, Kunle-Olowu OE. Anti-microbial susceptibility pattern of micro-organisms associated with urinary tract infections in a tertiary health institution in the Niger Delta Region of Nigeria. African J Microbiol Res. 2012; 6: 4976-4982.

[5] Fink R, Gilmartin H, Richard A, Capezuti E, Boltz M, Wald $\mathrm{H}$. Indwelling urinary catheter management and catheter-associated urinary tract infection prevention practices in Nurses Improving Care for Healthsystem Elders hospitals. Am. J Infect Control. 2012;40(8):715-720

[6] Sumera Sabir, Aftab Ahmad Anjum, Tayyaba Ijaz,
Muhammad Asad Ali, Muti ur Rehman Khan, and Muhammad Nawaz. Isolation and antibiotic susceptibility of E. coli from urinary tract infections in a tertiary care hospital. Pak J Med Sci. 2014 Mar-Apr; 30(2): 389-392.

[7] 8809911JAA(01) 2012-03 CLA COMPLEXTY:HGH CDC IDENTIFIER CODES ANALYTE:0412 TEST SYSTEM:07919.

[8] Kass EH. Pyelonephritis and bacteriuria. A major problem in preventive medicine. Ann Intern Med. 1962; 56: 46-53. Kass EH. Pyelonephritis and bacteriuria. A major problem in preventive medicine. An Intern Med.1962; 56: 46-53.

[9] Buchanon RE. Gibson NE (1974) Bergey's Manual of Determinative Bacteriology, $8^{\text {th }} \mathrm{ed}$. Williams and Wilkins Co. Baltimore. Page: 530-534.

[10] Holt JG, Krieg NR, Sneath Pha, Staley JT, Williams ST (2000) Bergey's manual of determinative bacteriology, $9^{\text {th }}$ ed. Lippincott Williams and Wilkins, Baltimore. Pp-532,549-551,559,576,592.

[11] Bauer AW, Kirby WMM, Sherris JC, Turck M. Antibiotic susceptibility testing by standard single disc method. Am J Clin Pathol. 1966; 45: 493-496.

[12] Clinical and Laboratory Standards Institute: Performance standards for antimicrobial susceptibility testing; seventeenth information supplement. CLSI document M100S17, Clinical and Laboratory Standards Institute Waynne Pennsylvania. 2014.

[13] Akram M, Shahid M, Khan AU. Etiology and antibiotic resistance patterns of community-acquired urinary tract infections in J N M C Hospital Aligarh, India. Ann Clin Microbiol Antimicrob. 2007;6:4

[14] . Hasan AS, Nair D, Kaur J, Baweja G, Deb M, Aggarwal P. Resistance patterns of urinary isolates in a tertiary Indian hospital. J Ayub Med Coll Abbottabad. 2007; 19: 39-41.

[15] Kothari A, Sagar V. Antibiotic resistance in pathogens causing community-acquired urinary tract infections in India: A multicenter study. J Infect Dev Ctries. 2008; 2: 354-8.

[16] Biswas D, Gupta P, Prasad R, Singh V, Arya M, Kumar A. Choice of antibiotic for empirical therapy of acute cystitis in a setting of high antimicrobial resistance. Indian J Med Sci. 2006; 60:53-8.

[17] Sabina Mahmutovic Vranic and Aida Uzunovic. Antimicrobial Resistance of Escherichia Coli Strains Isolated From Urine at Outpatient Population: A Single Laboratory Experience...Journal of the Academy of Medical Science of Bosnia and Herzegovina2016 Apr; 28(2): 121-124.

[18] Adib N, Ghanbarpour R, Solatzadeh H, Alizade $H$. Antibiotic resistance profile and virulence genes of uropathogenic Escherichia coli isolates in relation to phylogeny. Trop Biomed. 2014 Mar; 31(1):17-25. 